Musings

\title{
Musings on genome medicine: the slow but inexorable process of medical care reform in the United States
}

\author{
David G Nathan and Stuart H Orkin
}

Address: Dana-Farber Cancer Institute, 44 Binney Street, Boston, MA 02115, USA.

Correspondence: David G Nathan. Email: david_nathan@dfci.harvard.edu

\begin{abstract}
The current healthcare system in the United States is unsustainable, but any attempts at improvement must be carefully managed to avoid weakening the country's contribution to biomedical science research and the future of genome medicine.
\end{abstract}

The current struggle to achieve a rational healthcare system in the United States (US) may well have a profound effect upon the future of genome medicine and all advanced biomedical science. The current system is all but unsustainable, but if, in a poorly conceived attempt to improve it, the budgets of academic teaching and research hospitals are damaged, advances in medicine of any kind will be slowed to a crawl. Worldwide discoveries in medicine depend on the biomedical research productivity of Western Europe, Great Britain, Australia, Japan and North America, with growing contributions from Southeast Asia, China and India. The US effort is the largest in that group. A budget crisis in clinical care within leading US academic hospitals will imperil their capacity to do research because it is impossible to do meaningful research and break even financially in the process. It is axiomatic that institutions will lose at least $10 \%$ of research budgets because grantors either cannot or will not support the infrastructure that enables research activity. The gap between cost and revenue is made up by donations and/or by a surplus on the clinical side of the budget. If the clinical budget enters a red zone, donations will necessarily be directed to shore up that vital function. Unless donations can be markedly increased, this shift will inexorably weaken the research program and force it into mediocrity. This says nothing about the teaching and training budget, the remaining obligation of an academic hospital and one that is notoriously under-reimbursed. Clearly, a collapse of the clinical budgets of major academic hospitals in the US will have a very deleterious effect on worldwide medical progress, and genome medicine will suffer along with other critically important fields. Despite the obvious risk to academic medicine, reform must occur, but it must be achieved wisely.

In order to develop policies, governments must first ask the right questions. It is abundantly clear to anyone who cares to look that the US has a perfectly terrible healthcare system. Yes, we are very good at advances in medical technology. In fact it is well accepted that high-tech medical care is of excellent quality (if over-applied) in the US. But the nation has a relatively poor record in primary and preventive care. Hence the US has a vastly swollen per capita medical care cost structure and, as well, rates quite poorly in standard outcome measurements of the quality of medical care. This discouraging record has been well known for decades and has been exacerbated ever since Lyndon Johnson signed Medicare into law. The more patients we add to our defunct system, the higher the cost per patient and the poorer our results. If a medical care delivery system is broken, adding more patients to it is scarcely a prescription for correction. It is instead a march to insolvency.

Medical care in the US was largely either useless or dangerous until the advent of World War II. True, surgeons could be effective managers of patients with accessible and mechanically reparable organ dysfunction, but, as well described by Paul Starr in his classic book, The Social Transformation of American Medicine [1], the chances of a favorable encounter with a physician were low until the chemical and pharmaceutical industries introduced antibiotics in the late 1930s. Prior to World War II, academic medical science was largely explored in Europe, particularly in Great Britain, France and Germany. Indeed, in the first decade of the 1900s, only three institutions made important contributions to US medical science. These were Johns Hopkins, the University of Michigan, and what became the Rockefeller University. The other great modern contributors were either unborn or of inferior scientific productivity - that includes our own home, Harvard Medical School. Abraham Flexner's lugubrious 1910 report on the state of the nation's medical schools makes that point abundantly clear. World War II and Truman's decision to expand medical research in universities initiated the remarkable expansion of biomedical science in this country.

World War II also created a turning point in medical care delivery in several ways. In Europe and Great Britain, the 
vast disruption of civilian life created a need for national health services in order to prevent and treat serious communicable diseases. Once such systems were installed, there was no turning back. Civilian life was far less disrupted in North America, but Saskatchewan Province had a different problem. The province was thinly populated and unattractive to physicians. In response to its chronic deficiency of medical access, the province introduced a state-sponsored healthcare system to provide care for its citizens. Other provinces with inadequate medical access looked at Saskatchewan and decided to emulate it. The result is the Canadian system, which works extremely well except that it is underfunded.

The war impacted medical care in the US differently. A labor shortage resulted from the military draft and the vast expansion of arms production. To attract workers in the face of strict price and wage controls, factories offered fringe benefits, among them health insurance. Thus was born the now pernicious employer-based health insurance system that we endure today - pernicious because it is a tax-free benefit that encourages overuse by both patients and fee-for-service-based physicians. As pointed out recently by the Dartmouth Institute for Health Policy and Clinical Practice [2], the group that has most carefully followed Medicare expenses in the US, discretionary decisions by physicians account for most of the massive variation in Medicare costs that are born in different parts of the country and were described so well recently by Atul Gawande [3]. These decisions are undoubtedly influenced by patients, who are in turn influenced (along with physicians) by consumer-directed advertising campaigns operated by pharmaceutical companies, physician groups and hospitals. Only a concerted and successful effort to educate physicians, hospitals, pharmaceutical companies and the public that they are killing the golden goose will lead the US out of a cost and over-treatment spiral that will wreck not only medical care, but also advances in medical science.

There are almost as many proposed solutions to this dilemma as there are copy-cat drugs in the pharmacopoeia. They range from 'the market will solve it and government is useless' philosophy of some Republicans (who seem to have learned nothing since the Great Depression) to procrustean rearrangements of medical practice espoused by Relman [4] and others. The mordant history of our efforts to achieve reform, from Roosevelt to George W Bush, is brilliantly described by Blumenthal and Morone [5]. Their fine book demonstrates that all of the proposals emanating from the gaseous environment on Capital Hill have been considered over and over again in previous administrations. None of them deal sufficiently with the central failure: the lack of cost control exerted by healthcare providers and patients. If cost control is not introduced and the leading academic hospitals are not protected as much as possible from the consequences, medical care will decline and advances in genome medicine or any other complex area will wither.

The political nightmare created by this Gordian knot is obvious. How does a president, caught up in a deep recession, global warming, a serious unemployment crisis, a massive and growing deficit and an eight-year war against a seemingly inexhaustible supply of terrorists begin an education campaign on healthcare policy without provoking confusion and outright anger in both the medical establishment and many of the patients who actually benefit (or in the latter case think they benefit) from the current mess? Cost control can only be achieved by behavioral changes. President Obama is a great educator. We have to pray that he can teach this course successfully. The curriculum will require a lot of time and patience and some clear rule changes in reimbursement. We should not expect substantial improvement for several years. But improvement will come - we cannot afford to go on as we are.

\section{References}

1. Starr P: The Social Transformation of American Medicine. New York: Basic Books; 1982.

2. Sutherland JM, Fisher ES, Skinner JS: Getting past denial the high cost of health care in the United States. $N$ Engl J Med 2009, 361:1227-1230.

3. Gawande A: Annals of medicine. The cost conundrum: What a Texas town can teach us about health care. New Yorker May 25, 2009.

4. Relman AS: Doctors as the key to health reform. $N$ Engl J Med 2009, 361:1225-1227.

5. Blumenthal D, Morone JA: The Heart of Power: Health and Power in the White House. Berkeley: University of California Press; 2009.

Published: 12 October 2009

doi:10.1186/gm94

(C) 2009 BioMed Central Ltd 